PONTIFÍCIA UNIVERSIDADE CATÓLICA do RIO dE JANEIRO

\title{
A influência da música de fundo na intenção de compra dos consumidores em propagandas de perfume
}

\section{Gabriela Oliveira Correa e Silva}

Trabalho de Conclusão de Curso

Centro de CIÊNCIAS SOCIAIS - CCS

DEPARTAMENTO DE ADMINISTRAÇÃO

Graduação em Administração de Empresas 


\section{A influência da música de fundo na intenção de compra dos consumidores em propagandas de perfume}

Trabalho de Conclusão de Curso

Trabalho de Conclusão de Curso, apresentado ao programa de graduação em Administração da PUC-Rio como requisito parcial para a obtenção do titulo de graduação em Administração.

Orientador(a) : Daniel Kamlot 


\section{Resumo}

Oliveira, Gabriela. A influência da música de fundo na intenção de compra dos consumidores em propagandas de perfume. Rio de Janeiro, 2017. Número de páginas 28.Trabalho de Conclusão de Curso - Departamento de Administração. Pontifícia Universidade Católica do Rio de Janeiro.

A música é uma arte que combina os sons de modo agradável, ao ouvido de uma pessoa, ou seja, uma sonoridade que atinge de diversas formas o público, podendo interferir de forma positiva ou negativa o sentimento de alguém. (Aurélio, 2001). Ao destacar as propagandas com músicas, o estudo ressalta como essa influência da música reflete na pessoa que assiste a propaganda, isto é, como a música cria um vínculo emocional com o público, fazendo-o recordar e memorizar a mensagem da propaganda. Logo, o objetivo deste artigo é analisar como a música influencia a intenção de compras das pessoas, numa propaganda de perfume importado, mostrando como a música é um elemento estratégico nas propagandas e anúncios de perfume, tendo como base, para este resultado, alguns estudos já existentes sobre esta temática.

Palavras- chave: Música, Intenção, Comportamento, Público 


\section{Abstract}

Oliveira, Gabriela. The influence of background music on consumers purchase intent on perfume publicity. Rio de Janeiro, 2017. Number of pages 28, Course Completion Work - Business Departament. Pontifical Catholic University Rio de Janeiro.

Music is an art that combines sounds in a pleasant way that can have a positive or negative effect on people.

By putting sounds in propagandas, this study highlights how the influence upon hearing music, reflects on the ones watching the propaganda in a way that it creates an emotional bond with the viewers, making them memorize the message on it.

The objective of this work is to analyze music's influence on customers buying behaviour in an international brand of perfume propaganda. It shows how music can be used as a strategic element in perfume's advertisement, based on previous works about this theme. 


\section{Sumário}

Sumário

1. O tema e o problema de estudo 2

1.1. Introdução ao tema e o problema do estudo 2

1.2. Objetivo do estudo 4

1.3. Delimitação e foco do estudo 4

1.4. Justificativa e relevância do estudo 5

2. Revisão de literatura $\quad 6$

2.1. Comportamento o consumidor 6

2.2. Processo de decisão de compra 9

2.3. Músicas nas propagandas 10

3. Metodologia 13

3.1. Tipo de pesquisa 13

3.2. Seleção dos entrevistados 13

3.3. Procedimentos e instrumentos de coleta de dados utilizados no estudo 14

3.4. Formas de tratamento e análise dos dados coletados para o estudo 14 3.5. Limitações do método

4. Apresentação e análise dos resultados 16

4.1. Descrição da amostra do questionário 16

4.2. Descrição e análise dos resultados 19

5. Conclusões e recomendações para novos estudos 27

5.1. Sugestões de futuras pesquisas 28

$\begin{array}{ll}\text { Referências Bibliográfica } & 29\end{array}$

Anexo: Questionário 31 


\section{O tema e o problema de estudo}

\subsection{Introdução ao tema e o problema do estudo}

Nas propagandas e anúncios é possível que se utilizem diversas ferramentas para atrair o público desejado para a marca ou produto apresentado. No sentido de atrair a atenção do público, as marcas utilizam de diversos mecanismos para encontrar a excelência na mensagem, por exemplo quando uma marca utiliza um pequeno anúncio com imagens fortes ou uma propaganda nas redes sociais que conte uma pequena história, emocionando o público, ou também, um anúncio numa revista com imagens que remetam ao luxo e poder. No âmbito da propaganda, a música tem um papel atrativo, fazendo com que essa sonoridade desperte um sentimento, emoção, lembrança, sonhos e imaginação na pessoa que assiste, podendo ser alusões ruins ou boas, ou seja, possuem um forte apelo emocional junto ao público.

De acordo com a legislação da agência nacional de vigilância sanitária, lei 6.360 (Brasil, 1976), os perfumes são produtos de composição aromática obtida à base de substâncias naturais ou sintéticas, que, em concentrações e veículos apropriados, tenham como principal finalidade a odorização de pessoas ou ambientes, incluídos os extratos, as águas perfumadas, os perfumes cremosos, preparados para banho e os odorizantes de ambientes, apresentados em forma líquida, gelificada, pastosa ou sólida. Por consequência, dominar a avaliação deste elemento é de uma grande complexidade, logo, os consumidores julgam alguns fatores como o preço, a marca, a influência do produto/empresa, de forma que se sintam mais seguros em relação à qualidade do perfume.

De acordo com a Euromonitor (2017), em 2016, no âmbito mundial, o Brasil ficou em quarto lugar em relação ao consumo de higiene pessoal, perfume e cosméticos, com destaque para os perfumes, que ficaram em segundo lugar, mostrando a abundância de consumo dos brasileiros mesmo em momentos de crise no país. 
Em 2016, ainda segundo a mesma fonte, o país fechou o ano com um crescimento de 4,8\%, em valores, $\mathrm{R} \$ 102.288$ milhões. Desta maneira, o setor contribuiu para a movimentação da economia, de maneira a se destacar sendo o $2^{\circ}$ setor industrial que mais investe em inovação e o $1^{\circ}$ setor que mais investe em publicidade, ou seja, um campo com forte influência no desenvolvimento da economia brasileira. Já em relação à evolução do mercado, em relação ao ano de 2015, o país passa por uma leve recuperação no setor, que encerrou 2016 com $-6 \%$ da queda real, frente a $-9 \%$ em 2015 , o que se deve a fatores como: lançamento de produtos que atendam cada vez mais à necessidade do mercado, ampliação do mercado de consumo masculino e utilização de tecnologia de ponta.

O setor de Higiene Pessoal, Perfumaria e Cosméticos (HPPC, 2014) aponta oportunidades de se beneficiar em US\$1 bilhão a US\$1,5 bilhão ao ano na balança comercial do mesmo, ao longo prazo, segundo pesquisa realizada pela Bain \& Company (2014), logo, apresenta uma tendência positiva frente a outros setores da economia. Para o ano vigente, 2017, a empresa de pesquisa Euromonitor projeta uma receita de US\$ 65 bilhões, que mostra um enorme faturamento para uma indústria que em sua maioria, é destacada pelas brasileiras Natura e Boticário e pelas estrangeiras, Unilever, Procter \& Gamble, Avon e L'Oréal.

De acordo com Associação Brasileira da Indústria de Higiene Pessoal, Perfumaria e Cosméticos (ABIHPEC, 2016), a indústria nacional de HPPC tem apresentado um crescimento médio deflacionado composto próximo a 11,4\% ao ano nos últimos 20 anos, tendo passado de um faturamento "Ex-Factory", que é a receita calculada de acordo com o preço da fábrica, líquido de imposto sobre vendas, de $R \$ 4$,9bilhões em 1996 para $R \$ 42$,6bilhões em 2015. O acesso das classes $\mathrm{D}$ e $\mathrm{E}$ aos produtos do setor, devido ao aumento de renda, tem papel importante nesse crescimento do mercado. Os novos integrantes da classe C passaram a consumir produtos com maior valor agregado; a utilização de tecnologia de ponta e o consequente aumento da produtividade, favorecendo os preços praticados pelo setor, que tem aumentos menores do que os índices de preços da economia em geral; lançamentos constantes de produtos atendendo cada vez mais às necessidades do mercado foram alguns dos motivos para o resultado significante do mercado. 
Tendo em vista esse contexto, o presente estudo pretende buscar responder à seguinte questão: Como a música de fundo na propaganda de perfumes influencia a intenção de compra dos consumidores?

\subsection{Objetivo do estudo}

Este trabalho tem como objetivo final analisar a relação entre a influência da música de fundo numa propaganda de perfume e a intenção de compra do consumidor.

\subsection{Delimitação e foco do estudo}

O estudo em questão fica limitado a jovens e adultos das classes A, B e C, residentes no Brasil, mais especificamente no Rio de Janeiro, entre a faixa de idade de 18 a 60 anos, que consumam perfumes.

Este estudo tem como foco abordar a questão de como a música pode influenciar o público tanto positivamente como negativamente, ou seja, como uma propaganda com fundo musical pode atrair ou afastar o consumidor na intenção de compra de um perfume. Pretende-se compreender o quanto essa relação tem importância no comportamento do consumidor e como ela atinge o público na condição de alterar a sua intenção especificamente quanto à compra de perfume, vale ressaltar que ouros produtos não serão analisados.

Tal aspecto de análise se mostra interessante e importante porque o fator música se faz muito presente na vida das pessoas, e muitas vezes associado a momentos, histórias, sentimentos, lembranças e, desta maneira, pode combinar com uma propaganda que tem uma música que remeta a esse estado emocional, logo, o público pode vincular a propaganda a um momento que vivenciou.

As delimitações dos tipos de perfume que serão usados na análise serão os fatores preço e marca. No quesito preço, o intervalo será de $R \$ 180,00$ a 
$R \$ 390,00$, que apresenta uma ligação direta com as marcas, que, em sua maioria, traçam o perfil de seus consumidores por meio dos preços. Já as marcas selecionadas, restringem-se a Cacharel, que pratica o preço mais baixo do intervalo sugerido e Carolina Herrera, que abrange o valor mais alto do intervalo.

\subsection{Justificativa e relevância do estudo}

O presente estudo é relevante para diferentes públicos, dado o panorama da economia brasileira. Segundo um estudo realizado pelo SPC Brasil (2016), o brasileiro escolhe cortar atividades de lazer em vez de gastos com a beleza, e em pleno cenário de crise a "indústria da beleza" consegue se destacar e voltar a crescer no ano de 2016. Por meio deste estudo, as empresas poderão analisar a relevância da música de fundo na propaganda em relação à intenção de compra do público-alvo e a importância da escolha do tipo de música na propaganda de perfume, de forma a atrair de forma correta o consumidor que deseja. Desta maneira, as empresas conseguirão conduzir seus empenhos para uma melhor excelência na produção de uma propaganda de perfume, conseguindo destacar suas criações para condições melhores e não prejudicando as finanças e o tempo de trabalho da organização.

Tendo em vista o estudo da importância da música, os produtores de música poderão ver, nesse ramo, uma oportunidade de divulgação, logo, é um estudo que também tem relevância para eles.

Em suma, o estudo pode ser interessante para outros tipos de indústria que têm certa relação com a de perfumaria, como a de higiene pessoal e cosméticos, que é um setor unificado (mas estudado e avaliado de forma separada também), e atrai, em sua maioria, um mercado bem próximo ao dos consumidores de perfume. 


\section{Revisão de literatura}

Neste capítulo, o trabalho discutirá o referencial teórico do estudo, que irá servir como base de análise de todo o conteúdo que será apresentado. Esta seção será dividida em três partes: o comportamento do consumidor, a intenção de compra do consumidor e a teoria de música nas propagandas.

Foram abordados aspectos relacionados ao comportamento do consumidor, pontos como os estímulos sensoriais, memória e também no que se refere a intenção de compra do consumidor, além da discussão sobre essas ferramentas do marketing, os conceitos das músicas nas propagandas também serão temas de estudo para entender a relevância da música de fundo nesse cenário de propagandas de perfume.

\subsection{Comportamento o consumidor}

Com um mercado cada vez mais competitivo e dinâmico, as empresas buscam cada vez mais estudar as ferramentas de marketing que, de fato, trazem um valor agregado completo em relação à marca e ao público, ou seja, buscam conteúdos que façam uma análise mais robusta para obter resultados mais significativos, por isso o destaque para o comportamento do consumidor.

O comportamento do consumidor, segundo Schiffman e Kanuk (2010), é o estudo de como os indivíduos tomam decisões de gastar seus recursos, sendo eles, o tempo, esforço e dinheiro. É preciso destacar as frequências de uso de um produto e o porquê, quando e onde compram e consomem o produto, logo, é uma análise completa do comportamento do um indivíduo no consumo de um produto ou serviço.

De acordo com Solomon (2011), o comportamento do consumidor é um processo contínuo, isto é, não se limita ao instante do comportamento em que o consumidor compra o produto e o recebe em troca. O comportamento do consumidor engloba essa troca, e as interferências antes e depois da compra, o que traz para o pesquisador ou empresa que avalia e estuda o seu público, um 
cuidado com todo o processo de divulgação da marca, pois o comportamento do consumidor está presente em todos eles.

Outro ponto relevante, destacado por Solomon (2011), é o conteúdo gerado por consumidores e/ou pessoas, que não necessariamente consomem aquele produto, mas expressam a sua opinião sobre alguma marca, empresa ou produto nas mídias sociais e acabam criando conteúdo para a marca. Ainda de acordo com Solomon (2011), essa nova tendência é caracterizada pela era WEB 2.0, que coloca a internet como um meio social e interativo na atualidade, por meio de uma geração marcada por jovens que usam mídias sociais como o Facebook e o Youtube, considerados emissores de todo o tipo de informação. Logo, esses destaques fazem referência a uma geração muito conectada a produções de conteúdos mais autênticos, que mexam com os sentimentos, histórias e momentos, para que os consumidores se sintam vinculados com aquela mensagem e compartilhem nas redes sociais. As características de um indivíduo, culturas e estilo de vida, ajudam a determinar o significado atribuído às mensagens transmitidas nas propagandas ou anúncios. São impulsionados pelos desejos e necessidades, influenciando a maneira como interpretam aquela propaganda.

A sensação, ainda por Solomon (2011), está relacionada diretamente com as reações dos receptores sensoriais (olhos, nariz, boca, ouvidos e dedos) a estímulos que instigam esses sentidos, como por exemplo, quando uma marca tem um cheiro bem particular, é possível lembrar da marca só pelo aroma, isto é, essas sensações geram experiências internas e trazem à sua lembrança algo específico e particular. Como ilustrado na figura 1 , o consumidor recebe 0 estímulo externo no primeiro momento, por meio de imagens, sons, odores, gostos e texturas, e, após esse contato, os cinco sentidos do consumidor detectam os dados recebidos e dão início a um processo interno de lembranças, sensações e sentimentos. Estes processos são, como visto na imagem, seguidos da exposição, que diz respeito ao contato com o estímulo, à atenção, que está relacionada ao grau em que a experiência é dedicada a estímulo específico. 
Figura 1: Visão geral do processo perceptivo

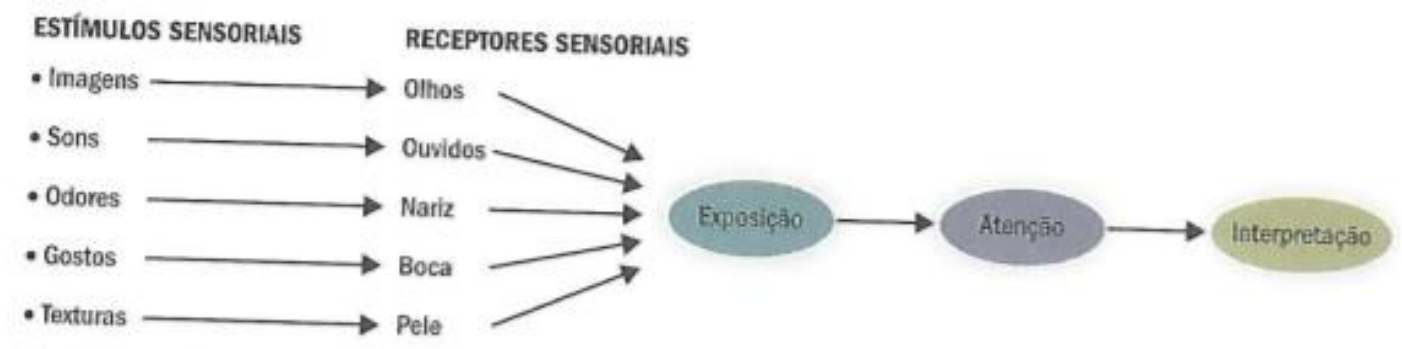

Fonte: SOLOMON, Michael, 2011, p 83

Embora todos os receptores sensoriais tenham sido citados, o trabalho presente dará ênfase ao som. Solomon (2011, p.90) cita que "muitos aspectos do som (pelo menos os que conseguimos ouvir) afetam os sentimentos e comportamentos das pessoas". Isto é, ao ficarem expostos a estímulos sensoriais (sons), os consumidores passam a associar uma viagem especial, por exemplo, ao se depararem com uma propaganda de companhia aérea contendo uma música específica que remeta àquele momento, que de certa forma, acaba criando um certo vínculo emocional com a empresa.

Solomon (2011, p. 131) explica ainda que a memória envolve um "processo de aquisição e armazenagem de informações de modo que estas estejam disponíveis quando necessárias. "Nos três estágios apresentados, o primeiro é aquele em que o consumidor identifica a informação e a coloca na memória, esse chamado de estágio de codificação. No segundo momento, a informação é gravada na memória do indivíduo, chamado de armazenagem, e por último, no processo de recuperação, o indivíduo busca as informações que Ihe interessam. Neste estudo, ao destacar a memória, é possível relacioná-la com o dinamismo da geração, ou seja, é preciso que a marca aplique um processo contínuo de referência a memórias, para que não caia no esquecimento, frente a um contexto de informação a todo momento. 


\subsection{Processo de decisão de compra}

De acordo com Solomon (2011), o processo de decisão de compra de um produto envolve cinco etapas. O reconhecimento do problema é o primeiro estágio, ou seja, o indivíduo entende que alguma ação precisa ser tomada ou não; ao perceber que deve agir, o indivíduo parte para a segunda etapa, que é a busca por informações, que é a consulta por diversas fontes de forma a coletar 0 máximo de informações, como a marca e qualidade, por exemplo. Logo após, segue o estágio de avaliação de alternativas, que abrange o conjunto das opções escolhidas pelo indivíduo, seguida da etapa de decisão de compra, na qual o consumidor determina qual ou quais produtos tem a intenção de comprar. $\mathrm{Na}$ etapa final, classificada como comportamento pós-compra, ou seja, após a utilização do produto, o indivíduo consegue avaliar o produto por sua totalidade, desde o momento em que escolheu o produto até o pós-consumo. Essa última etapa é de grande importância, porque a partir dela, o indivíduo toma uma atitude negativa ou positiva relacionada a sua experiência com o produto, podendo indica-lo para um amigo e virar um consumidor ativo do produto.

No que diz respeito ao dinamismo da internet, Solomon (2011) relata que o modo como os consumidores decidem comprar algo está mudando, pois os chamados cibermediadores podem coletar muitas informações num período relativamente curto, para que as empresas filtrem as informações apenas aos dados mais importantes o que acaba também simplificando o processo de decisão.

Os critérios de avaliação, para Solomon (2011, p. 351), estão relacionadas " às dimensões utilizadas para julgar os méritos de opções concorrentes”, ou seja, o consumidor pode escolher algum produto por gostar da marca, ou escolher o produto só porque todos utilizam aquele produto. Existe uma enorme lista de fatores que levam o indivíduo a avaliar um produto. É importante destacar que produtos que tenham algo que os diferencie dos outros têm mais chance de serem os escolhidos no processo de decisão no qual as alternativas são similares. Essa situação pode levar o consumidor a analisar os atributos determinantes, que segundo o mesmo autor, são as características que efetivamente são utilizadas para considerar as diferenças entre todas as opções, 
ou seja, são aqueles atributos que se destacam num conjunto de produtos com características semelhantes.

De acordo com Mintel Market Sizes,(2016), o Brasil continua como um dos maiores mercados de perfumaria do mundo, com uma estimativa em dezembro de 2016, de US\$ 4,38 bilhões de vendas em valor no varejo. De acordo com a mesma fonte, os consumidores mais adultos tendem a atentar para questões como a de procura por produtos que tenham preocupações em hidratar a pele e sejam menos agressivos ao corpo. Para Karsaklian (2011), existem os consumidores que procuram fontes internas e outros, as externas de informação. As fontes internas seriam as memórias, experiências que o próprio indivíduo tenha vivenciado, pode ser com uma marca específica, produto em si ou embalagem, que tenham um laço emocional com o indivíduo. Já quanto às fontes externas, a autora destaca propagandas, indicação de amigos ou pessoas influentes que podem influenciar na decisão da escolha de um perfume. Em suma, para Karsaklian (2011), o ato de compra é resultado de uma ação que une as duas fontes, já que o consumidor é influenciado por suas experiências e pela sociedade.

Importante ressaltar que toda a experiência com a compra é relacionada à sensibilidade do indivíduo, ou seja, o ambiente, o aroma do local de venda, a forma como estão organizados na loja e todas as outras técnicas utilizadas para atrair o consumidor são fatores que podem influenciar na experiência positiva ou negativa com a marca/produto.

\subsection{Músicas nas propagandas}

Para Oakes (2007), a relação entre a música de fundo e a mensagem da propaganda devem ser complementares e não competir entre si, de forma a ter harmonia, clareza e gerar um impacto positivo para o indivíduo, para que, o mesmo tenha uma imagem positiva da marca. É importante destacar que numa propaganda ou anúncio, a ilustração das imagens e a canção devem apresentar sincronia e harmonia, para que a mensagem seja transmitida corretamente e o indivíduo não se perca com informações soltas ou excessivas. 
Em relação à escolha de tipos de música, é possível destacar as músicas populares, que são aquelas que são mais acessíveis a todo o tipo de público. Roehm (2011) destaca que estudos confirmam que à medida que certo artista ou música ficam mais famosos, ou populares, maior é a atenção e a memorização do produto. Por exemplo, a propaganda do Dia das Mães 2017 da empresa Riachuelo, que usou uma música da cantora Ludmilla (link indicado na bibliografia). Neste caso, a canção famosa é a mesma, mas a mensagem não, tendo sido alterada para a campanha publicitária.

Descobrir as forças que movimentam a escolha do consumidor é de extrema importância para o marketing. Se partirmos do propósito que, em geral, as músicas populares apresentam uma parte instrumental acompanhada de letras cantadas, é possível concluir que o consumidor pode se familiarizar mais com essas canções. De acordo com Roehm (2001), quando os indivíduos estão familiarizados com uma música, a lembrança da mensagem é mais eficaz quando usada em uma versão instrumental. A autora acredita que seja por conta da vontade do consumidor em cantar a música, que está omissa, e assim interpreta a mensagem que a marca está passando no anúncio. Relacionando com o tópico acima, o indivíduo busca, no estágio de recuperação, informações associadas àquela música e associa a algum momento, história ou sentimento. Por outro lado, a autora faz referência também às pessoas que não conhecem a música, e como não conhecem a letra para cantar, necessitam de palavras para entenderem a mensagem do anúncio, ou seja, para essas pessoas, a versão cantada seria mais eficaz do que a instrumental.

Para Allan (2006), a música, como uma banda ou música de fundo, está integrada aos anúncios de diversas formas, e muitas vezes a música é produzida, ou seja, escrita e gravada, para certos produtos relacionados. Hoje, as marcas se utilizam da música como uma forma de se aproximar cada vez mais do público do produto ofertado. Muitas vezes a própria empresa pesquisa sobre os interesses, costumes antigos (de infância, rotinas por exemplo) dos consumidores e expressa de maneiras diferentes numa propaganda que acaba auxiliando na identidade e aproximação da marca com o consumidor. Em destaque, Allan (2007) esclarece que uma das formas mais comuns da utilização da música em publicidade é o recurso de músicas populares cantadas e/ou instrumentais, que se diferenciam da seguinte forma: A canção cantada na sua versão original: a canção é usada com letra e música originais e associada a um 
produto ou serviço; A canção cantada numa versão alterada: a letra original é substituída por uma outra adaptada ao produto; E a instrumental, na sua versão original.

Outro assunto de relevância são os jingles, que para Bullerjhan (2006) são músicas, geralmente com melodias pequenas e simples, para promover uma marca ou um produto. Os jingles, na sua maioria, são compostos por letras fáceis, com rimas e com muitas repetições para que o público os assimile e memorize com mais rapidez e facilidade, logo a empresa não precisa de uma grande estrutura de produção, e os consumidores acabam associando e memorizando mais rápido, tendo um maior retorno de interação com o consumidor, que muitas vezes pode também gerar conteúdo para a marca. A eficácia dos jingles refere-se ao fato do material da canção verbal ser utilizado de uma excelente forma fonética e não necessariamente com o processo semântico bem estruturado, ou seja, quando há poucas letras cantadas, o consumidor tende a relembrar com mais facilidade a informação. 


\section{Metodologia}

A seguir, o capítulo irá discutir sobre a metodologia adotada, apresentando o tipo de pesquisa, a seleção dos respondentes, a coleta e análise dos dados e as limitações do método selecionada.

\subsection{Tipo de pesquisa}

Para o presente estudo, a pesquisa realizada foi quantitativa, do tipo exploratória. De acordo com Malhotra (2011, p.22), "com a pesquisa quantitativa, o pesquisador encontra resultados conclusivos e que podem ser utilizados para recomendar um curso final de ações". Ao utilizar o tipo exploratória, o pesquisador tem como caminho descobrir e entender os problemas de forma mais próxima para, assim, levantar as hipóteses.

A coleta de dados da pesquisa foi feita através de quatro questionários realizados na plataforma MindMiners com as mesmas questões, mas com vídeos diferentes. Logo, um com um vídeo da propaganda do perfume Amor Amor, da Cacharel, com som e outro sem som, e outro do perfume $212 \mathrm{VIP}$, da marca Carolina Herrera, com som e outro sem som. Os questionários foram divididos e enviados para a base de dados da MindMiners, para buscar uma regularidade entre os resultados coletados e, assim, medir a influência que a música de fundo provoca e a intenção de compra dos consumidores quando a música de funcho está ou não presente na propaganda.

\subsection{Seleção dos entrevistados}

Os questionários foram divulgados da forma mais extensa possível, que foi a base de dados da plataforma MindMiners, para abranger uma amostra maior e mais diversificada da população. Foram alcançados 200 respondentes de diversos bairros do Rio de Janeiro e com idades de 18 a 41 anos. Em sua maioria, os respondentes eram do sexo feminino numa faixa entre 18 e 24 anos, moradores do Rio de Janeiro, da classe B2 com o ensino médio completo. 


\subsection{Procedimentos e instrumentos de coleta de dados utilizados no estudo}

Os quatro questionários foram criados e suas respostas computadas através da ferramenta especializada em pesquisas MinMiners, escolhida por se tratar de quatro questionários iguais, mas com apenas vídeos diferentes, logo, foi necessário buscar uma plataforma que tivesse um banco de dados considerável de respondentes com o perfil adequado, para tornar o trabalho mais diversificado e homogêneo. Como já ressaltado, foram realizados quatro questionários, sendo eles: Questionário 1, com a propaganda do perfume da Carolina Herrera sem a música e Questionário 2, com a mesma propaganda, mas com a música. E os questionários 3 e 4, com as propagandas de perfume da Cacharel com e sem música, respectivamente.

Desta maneira, depois que os questionários estavam prontos, a MindMIners, que já tem uma base de dados de usuários pronta para responder os questionários, os envia para a base, de forma aleatória e rápida.

\subsection{Formas de tratamento e análise dos dados coletados para o estudo}

O tratamento dos dados foi quantitativo. As informações obtidas através do questionário foram analisadas com base no referencial teórico presente no trabalho, e por meio de estatística descritiva com o uso de gráficos de porcentagem e média.

\subsection{Limitações do método}

As limitações encontradas no presente estudo refletidas na pesquisa, referem-se à busca de maiores informações do Referencial Teórico em relação à importância do som na venda e nas propagandas. Os estudos mais avançados e profundos do assunto, estão disponíveis em materiais caros e se encontram em inglês.

Por utilizar uma plataforma paga como a MidMiners, houve certa limitação nos tipos de questões, que não existiam tipo de questão na plataforma, e na 
quantidade de respondentes, que estava relacionada ao valor total a ser pago, que totalizou cinquenta respondentes para cada questionário. Outro fator relevante, é o fato de alguém já preferir uma das marcas apresentadas, o que poderia levar a respostas mais parciais. 


\section{Apresentação e análise dos resultados}

O presente capítulo, apresenta e analisa os principais resultados alcançados, discute suas implicações e produz sugestões sobre o estudo selecionado. É dividido em duas seções: Descrição da amostra do questionário e descrição e análise dos resultados.

\subsection{Descrição da amostra do questionário}

Com base no questionário montado e enviado, foi possível criar o perfil dos respondentes, com relação ao sexo, idade, renda familiar e grau de escolaridade. Vale ressaltar que as questões referentes a dados pessoais, foram deixadas por último nos questionários enviados aos respondentes.

O perfil do público pesquisado foi de $52 \%$ de mulheres e $49 \%$ de homens, como mostra no gráfico 1 :

\section{Gráfico 1: Sexo}

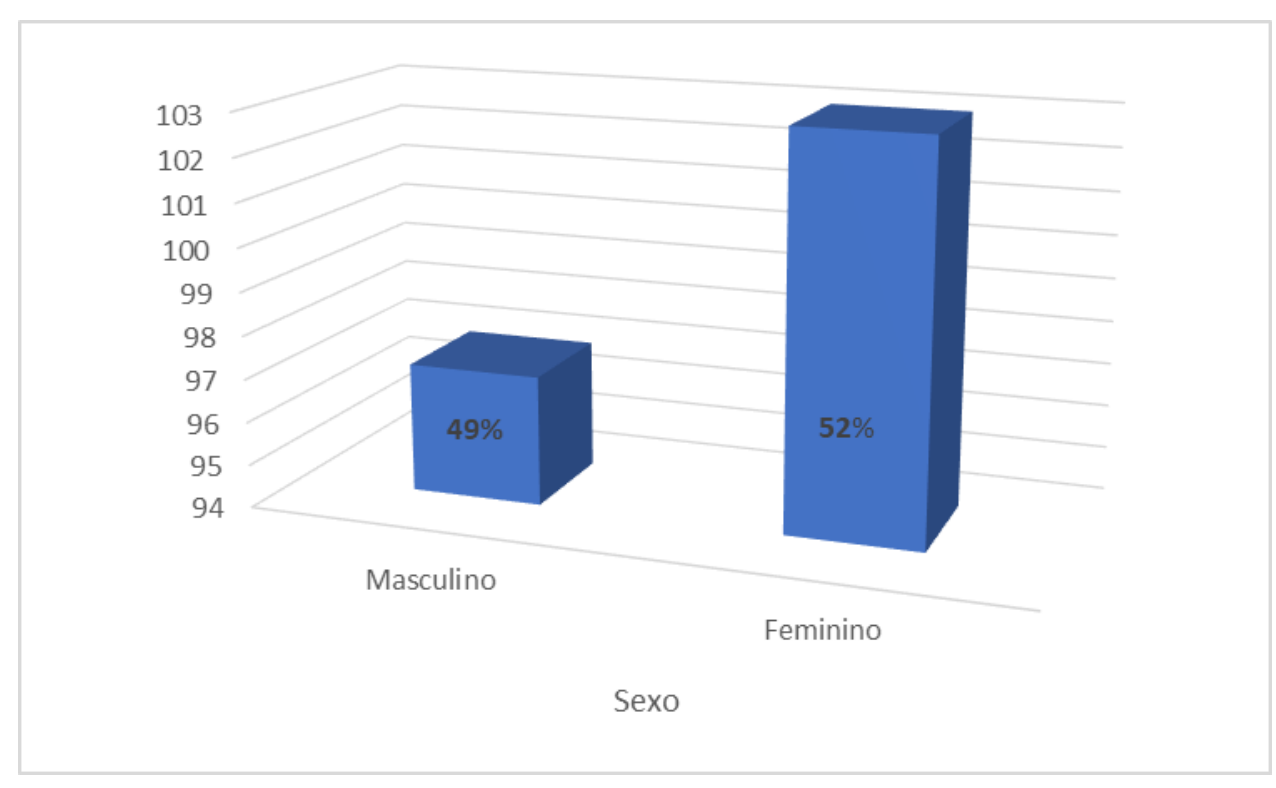

Ao analisar a questão de idade, é possível visualizar na tabela 1, que os resultados encontrados foram de uma média de 31 anos, sendo $34 \%$ dos respondentes no intervalo entre 18 e 24 anos, mas os outros intervalos de 
idades não mostraram números muitos distantes, o que mostra que o intervalo de idades não foi espaçado e que teve uma amostra das mais variadas idades.

Tabela 1: Idade

\begin{tabular}{|c|c|c|c|}
\hline Idade & Quantidade de respostas & Idade média & $\begin{array}{c}\text { Porcentagem do } \\
\text { total }\end{array}$ \\
\hline $18-24$ & 68 & 31 & $34 \%$ \\
\hline
\end{tabular}

Em relação à renda média familiar, de acordo com o gráfico 2, a maior parte dos respondentes, com $34 \%$ do total, tem a renda média familiar de até $R \$$ $1.576,00$. Os resultados seguintes não ficaram muito distantes, com $28 \%$ dos respondentes no intervalo de $R \$ 1576,01$ a $R \$ 3.152,00,21 \%$ no intervalo de $R \$ 3.152,01$ a $R \$ 7.880,00,15 \%$ no intervalo de $R \$ 7.880,01$ a $R \$ 15.760,00$ e $4 \%$ no intervalo de $R \$ 15760,01$ ou mais.

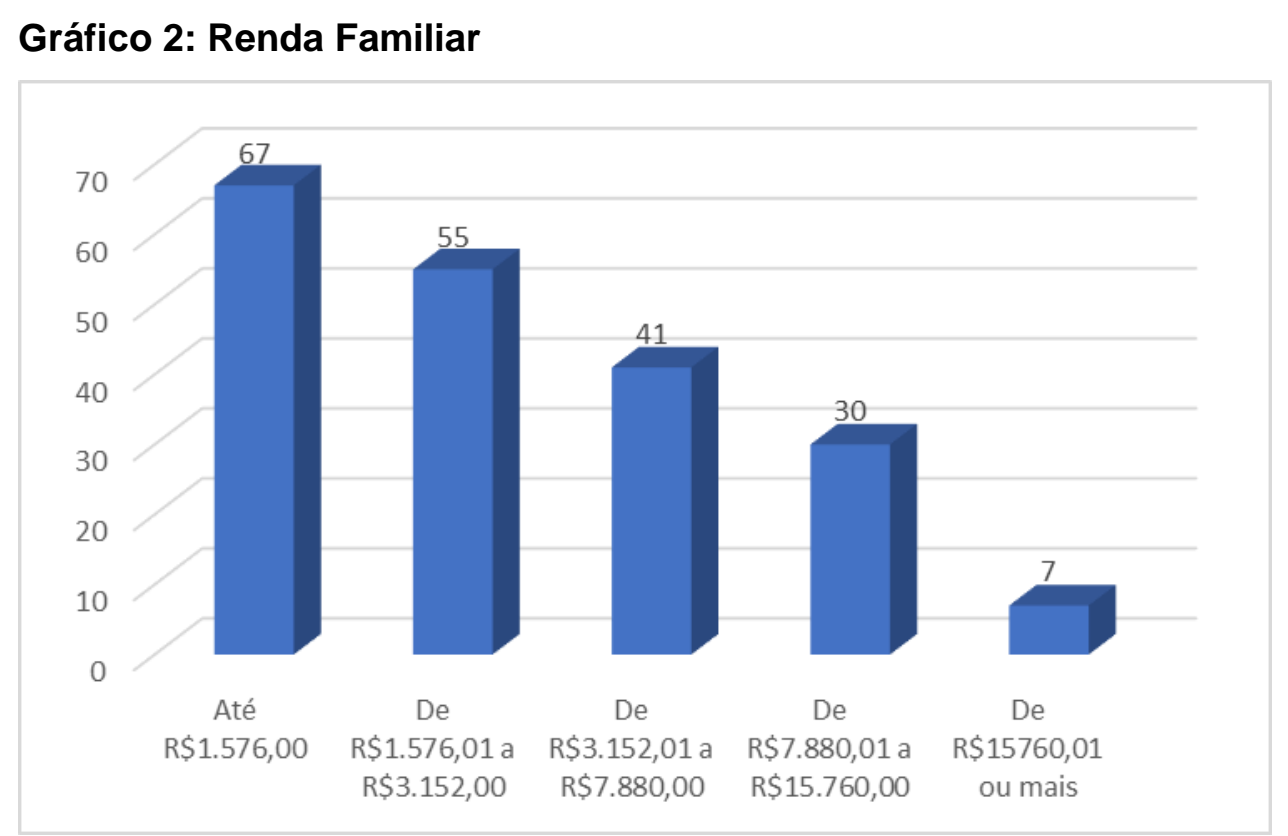

O questionário foi iniciado com a pergunta " Com que frequência você usa perfume?", para verificar a relação das pessoas com o uso de perfume. Segundo os resultados, como indicado no gráfico 3,43\% das pessoas utilizam perfume 7 vezes ou mais por semana e apenas $8 \%$ não usam perfume, ou seja, a relação das pessoas com o perfume é consideravelmente alta, já que quase metade das respostas foram levadas a um uso rotineiro do mesmo. 


\section{Gráfico 3:}

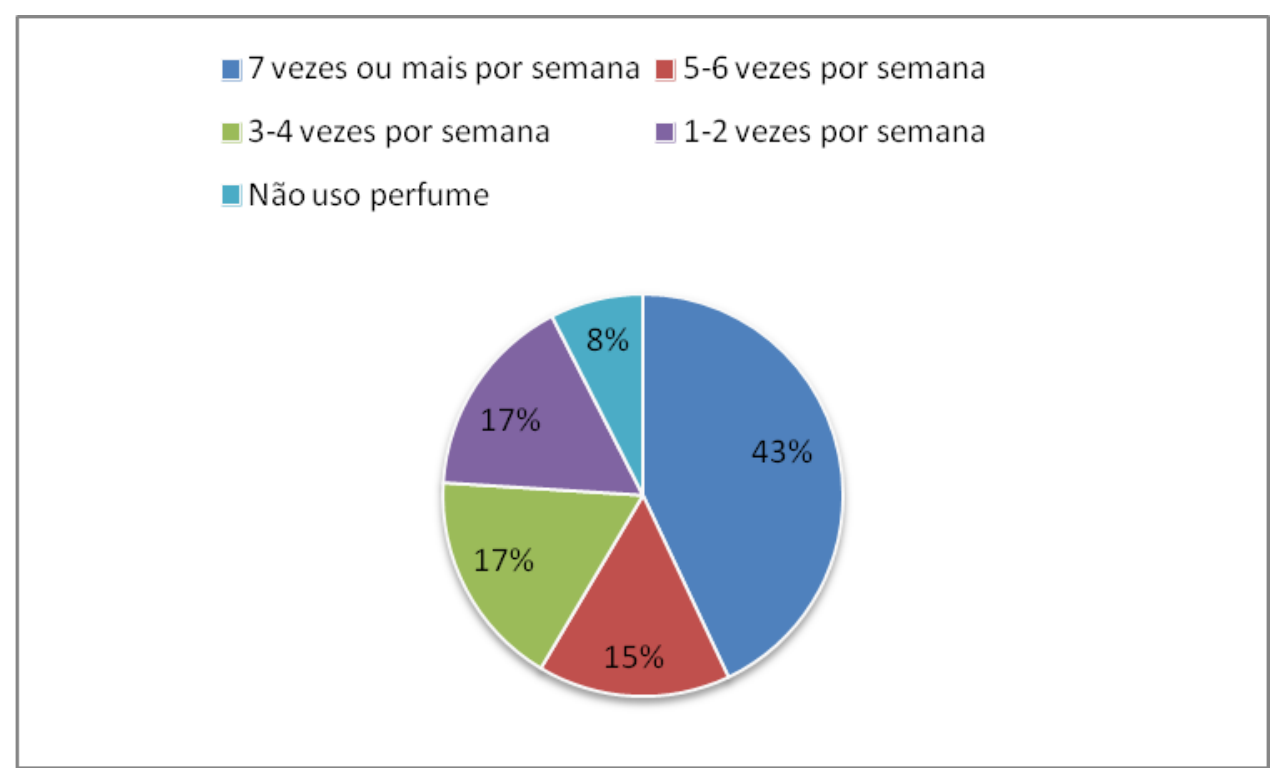

A questão seguinte, de resposta múltipla, consistiu em "O que você pensa de pessoas que usam perfume? ( Pode indicar mais de uma alternativa )". O objetivo foi entender qual seria a relação das pessoas que utilizam perfumes com os adjetivos e descrições citados no questionário.

De acordo com as respostas, indicado com o gráfico 4 , em média $30 \%$ se referem a opção "são pessoas vaidosas", seguida de uma média de 17\% respostas para as que "são pessoas sensuais" e uma média de $16 \%$ das respostas para as que "são pessoas sofisticadas". Por outro lado, as menores médias foram para: "São pessoas esnobes" com apenas $0,2 \%$ das marcação, "São pessoas que tomam poucos banhos" com apenas $1 \%$ e "São pessoas que têm problemas com odor" com $2 \%$ das escolhas;

Essa questão foi planejada para verificar sobre o que os respondentes pensam a respeito dos outros e também de si próprio, que ao fazer relação com a primeira questão, foi encontrado um número de $46 \%$ que utilizam perfumes de 7 vezes ou mais na semana, sendo possivel relacionar ao fato das pessoas se acharem mais vaidosas, sensuais e sofisticadas ao usar perfume. 


\section{Gráfico 4:}

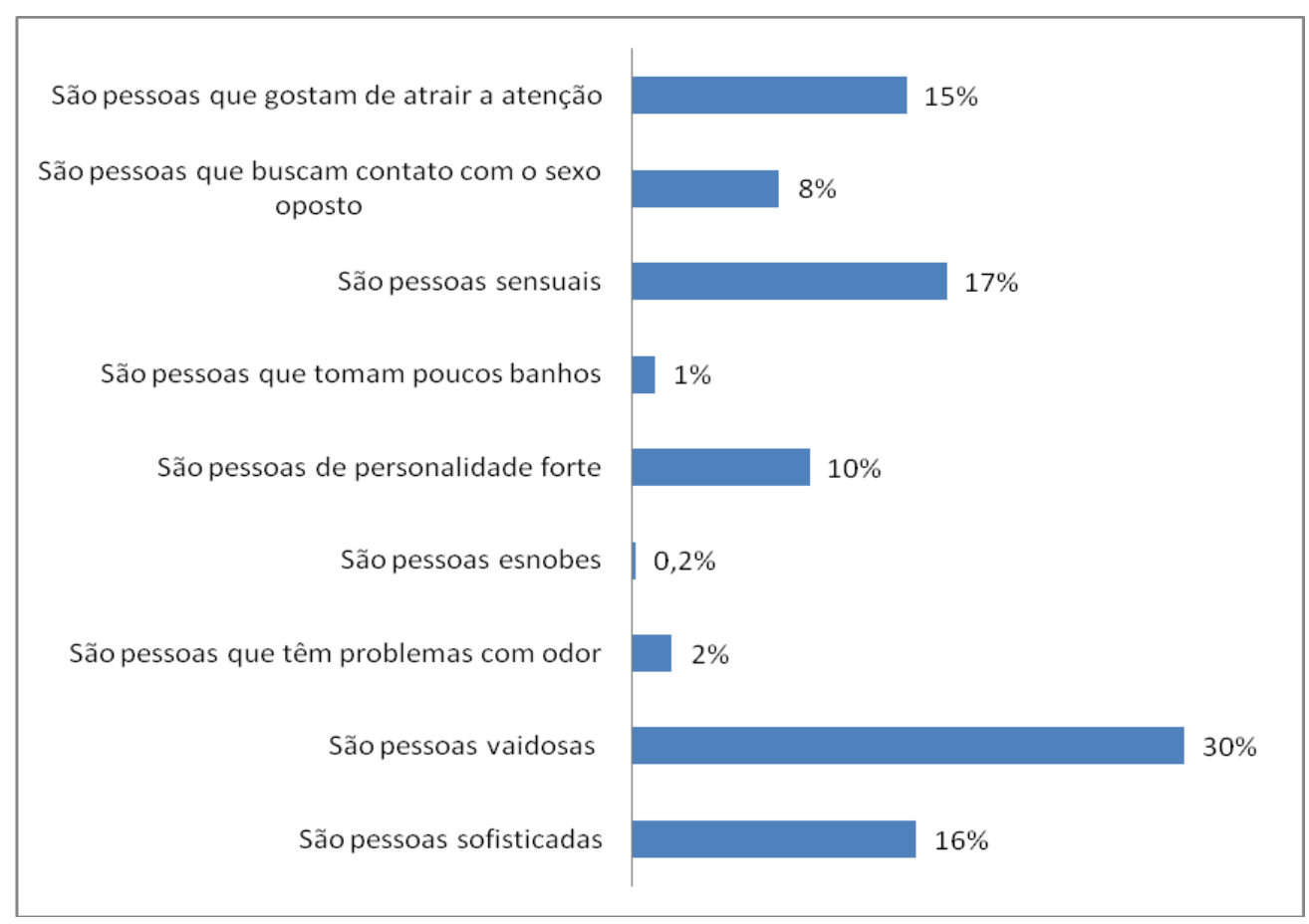

\subsection{Descrição e análise dos resultados}

A questão 3 tem certa particularidade, pois em cada questionário apresenta uma propaganda diferente mas com a merma pergunta, que se refere a: "Dê uma nota (de 1 a 5 ) para a propaganda que você acabou de assistir" e logo em seguida a pergunta " O que faltou nessa propaganda para você ?", que foi configurada como aberta para as pessoas se sentirem à vontade de escrever aquilo que realmente pensarem. A seguir, os resultados das duas questões, dos questionários 1, 2,3 e 4 respectivamente.

Em relação as duas marcas, de acordo com a tabela 2, as propagandas com música, tiveram $67 \%$ das respostas entre "muito boa" e "boa", já as propagandas sem música, ficaram com $60 \%$ das respostas entre o mesmo intervalo. Um fato curioso em destaque é que, as propagandas sem música tiveram $31 \%$ de respostas de "muito boa" e $29 \%$ das respostas consideradas "boa" , frente as propagandas com música, que ficaram com 22\% e 45\%, respectivamente, ou seja, as com música tiveram um número maior na opção "boa". 
Tabela 2:

\begin{tabular}{|l|c|c|}
\hline & Total com música & Total sem música \\
\hline 1 - Muito boa & $22 \%$ & $31 \%$ \\
\hline - Boa & $45 \%$ & $29 \%$ \\
\hline 3 - Mediana & $23 \%$ & $33 \%$ \\
\hline - Ruim & $5 \%$ & $4 \%$ \\
\hline - Muito ruim & $5 \%$ & $3 \%$ \\
\hline
\end{tabular}

Em referencia à propaganda do perfume 212 VIP, Carolina Herrera sem música, como indicado na tabela 3, 34\% apontaram a propaganda "mediana" e $58 \%$ respostas entre "muito boa" e "boa", na sequência, a pergunta aberta teve $22 \%$ das respostas como " não esta faltando nada", seguidos de $18 \%$ de respostas referentes a "Mais informações do produto e marca" .Ou seja, os resultados levaram a uma nota mediana, mas as pessoas não souberam dizer exatamente o que ficou faltando para dar uma nota melhor. Em relação a palavra “ música”, foi citada 4 vezes na questão, que equivale a $8 \%$ do total de respostas do questionário, o que mostra que foi levado em conta a falta de sonoridade na propaganda.

Ainda na mesma propaganda, mas com música, os resultados estão entre $60 \%$ entre "muito boa" e "boa", ou seja, as notas foram inferiores às propagandas sem música. Em contrapartida, 16\% apontaram respostas como "não faltou nada na propaganda" e 16\% com respostas referentes a "faltando mais informações do produto", ou seja, as notas foram inferiores à propaganda sem música, mas não foi relatado um número alto de uma mesma resposta além das destacadas acima.

Tabela 3:

\begin{tabular}{|l|c|c|}
\hline & 212 VIP sem & 212 VIP com \\
\hline $\mathbf{1}$ - Muito boa & $28 \%$ & $20 \%$ \\
\hline $\mathbf{2}$ - Boa & $30 \%$ & $40 \%$ \\
\hline $\mathbf{3}$ - Mediana & $34 \%$ & $26 \%$ \\
\hline $\mathbf{4}$ - Ruim & $4 \%$ & $8 \%$ \\
\hline $\mathbf{5}$ - Muito ruim & $4 \%$ & $6 \%$ \\
\hline
\end{tabular}


Em relação ao questionario 3, como indicado na tabela 4, na propaganda do perfume Amor Amor sem música, 62\% responderam com notas entre "muito boa" e "boa", e relacionada a questão seguinte, $24 \%$ disseram frases como " não esta faltando nada na propaganda" e 14\% informaram sentir falta de um som, que foi a informação com o maior número depois do "não faltar nada", o que talvez pode ter acarretado na nota da propaganda.

Já em relação a mesma propaganda mas com música, 74\% responderam entre "muito boa" e "boa", com destaque na questão seguinte, na qual $32 \%$ apontaram " não sentir falta de algo" e 16\% informarem que "faltou mais informação do produto". Esses números apontam notas melhores em relação à propaganda sem música, ou seja, o fator música no plano de fundo numa propanda, pode alterar a percepção positiva numa propaganda de perfume.

Tabela 4:

\begin{tabular}{|l|c|c|}
\hline & Amor Amor com & Amor Amor sem \\
\hline 1 - Muito boa & $24 \%$ & $34 \%$ \\
\hline 2 - Boa & $50 \%$ & $28 \%$ \\
\hline 3 - Mediana & $20 \%$ & $32 \%$ \\
\hline 4 - Ruim & $2 \%$ & $4 \%$ \\
\hline 5 - Muito ruim & $4 \%$ & $2 \%$ \\
\hline
\end{tabular}

Na questão seguinte, foi utilizado a escala de diferencial semântico com doze características mais o seu respectivo oposto. O uso da escala, foi escolhido para avaliar a percepção dos respondentes em relação as propagandas dos dois perfumes, com e sem música.

De acordo com os resultados, que diz respeito ao perfume Amor Amor, como indicado no gráfico 9 e na tabela 5 , os valores das notas encontrados ficaram bem próximos entre 2 e 3 , mas com destaque para as médias da propaganda com música, com resultados mais favoráveis que os da propaganda sem música. Em relação a propaganda com música, foi considerada mais cara, mas com uma pequena diferença entre os valores das notas de 0,56 , do que a sem música.

Outro destaque está no que diz repeito aos valores da propaganda com música serem considerados mais agradáveis e as sem músicas avaliadas com uma média alta de nota 4, como desagradável e na característica simples versus vaidoso, a propaganda com música apresentou uma média de nota 3,8 frente a 
da sem música de média de nota 3,46 , ou seja, uma diferença relativamente pequena mas considerável para destaque. Vale ressaltar que um dos fatores para notas mais medianas, pode, talvez ter relação com uma marca um pouco menos conhecida no Brasil e por conhecer pouco, os repondentes não tinham tanta certeza das características sugeridas.

Gráfico 9: "Em uma escala de 1 a 5 , selecione o que mais se aproxima ao que você pensa do produto exibido na propaganda:"

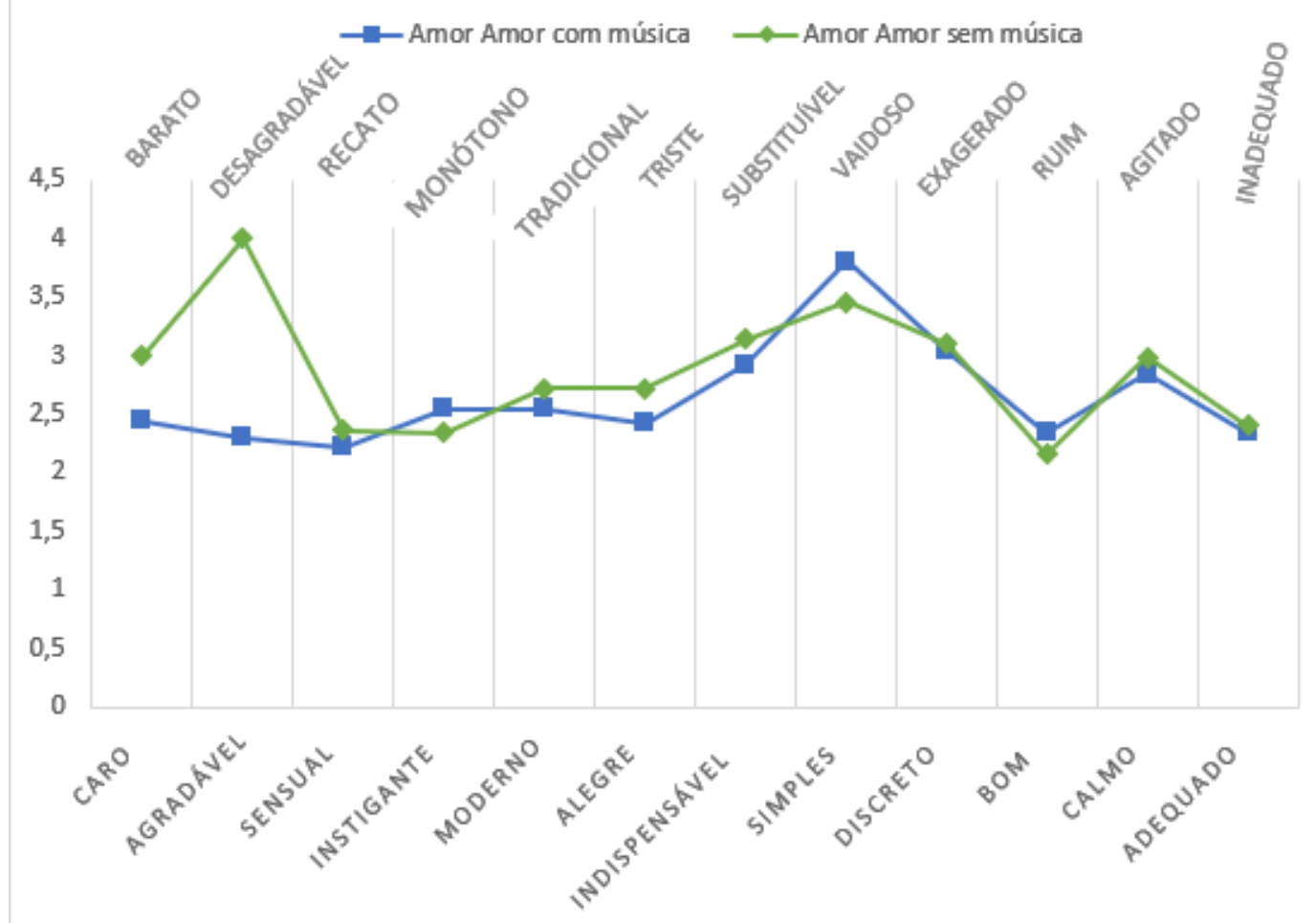

De acordo com os resultados, que diz respeito ao perfume $212 \mathrm{VIP}$, como indicado no gráfico 9 e na tabela 5 , tiveram resultados com médias de notas entre 1 e 2, o que mostra que seus valores ficaram mais próximos das características mais favoráveis do que a do perfume Amor Amor, o que talvez,pode ser explicado pela marca mais conhecida e/ou pelo preço deste produto ser mais alto.

Um fator curioso, é que entre as características simples versus vaidoso, a propaganda sem música foi considerada mais vaidosa com uma média de nota 4,28 em relação a propaganda com música, que foi considerada mais simples, com uma média de 1,74 seguida das notas entre exagerado versus discreto, que foram apresentados notas médias de 3,96 na propaganda sem música e 3,84 na 
propaganda com música, ou seja, um ponto controverso no sentido da propaganda com música, pois ao mesmo tempo que acharam bem simples, acharam bastante exagerado. Em compensação, entre calmo versus agitado, a propaganda com música apresentou uma nota média bem maior do que a sem música, de 4,14 e 1,1 respectivamente.

Gráfico 10: "Em uma escala de 1 a 5 , selecione o que mais se aproxima ao que você pensa do produto exibido na propaganda:"

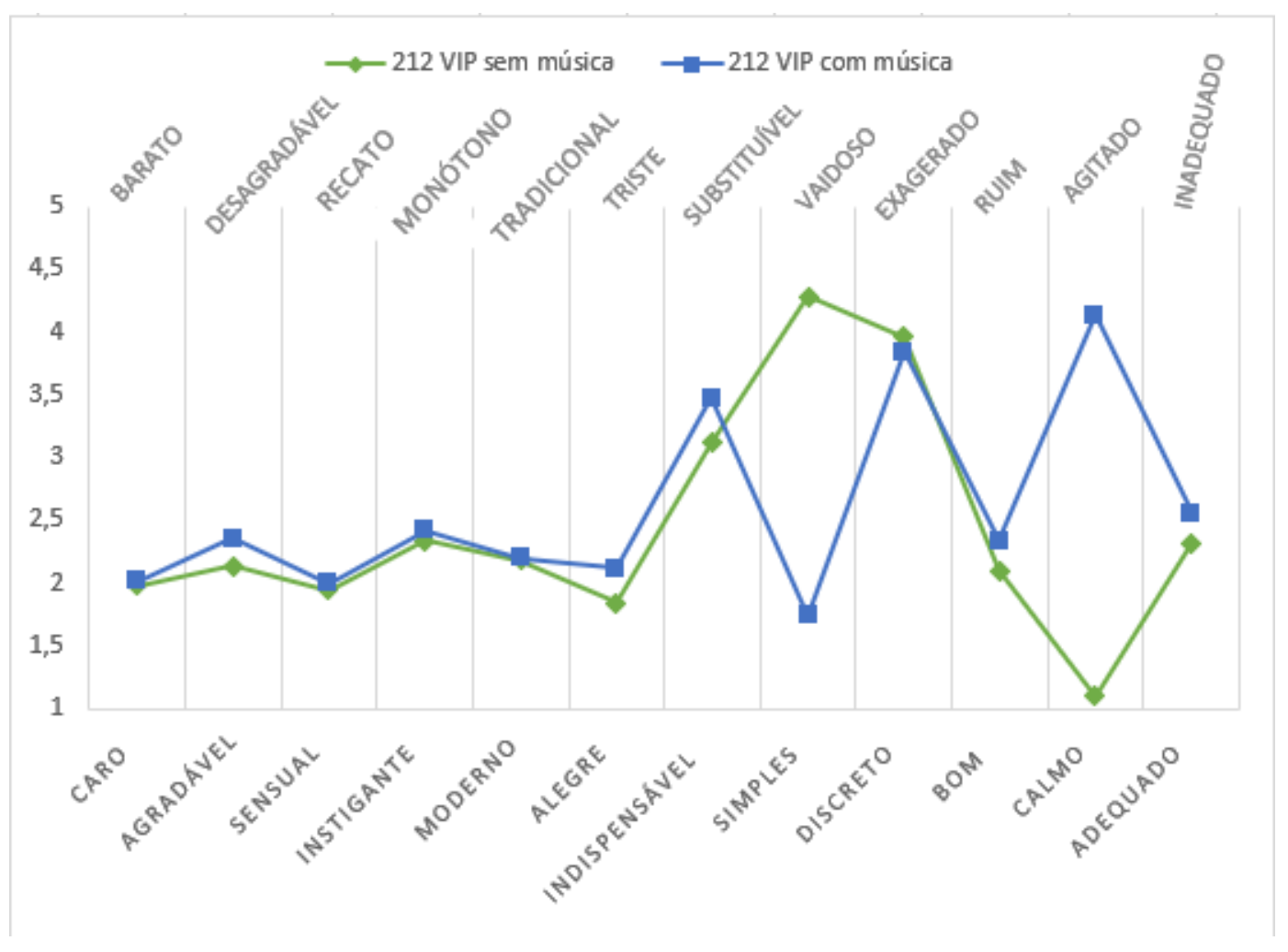


Tabela 5:

\begin{tabular}{|l|c|c|c|c|c|}
\cline { 2 - 6 } \multicolumn{1}{l|}{} & \multicolumn{4}{c|}{ Média ponderada } & \\
\hline & $\begin{array}{l}\text { Amor Amor sem } \\
\text { música }\end{array}$ & $\begin{array}{l}\text { Amor Amor com } \\
\text { música }\end{array}$ & 212 VIP sem música & 212 VIP com música & \\
\hline Caro & 3 & 2,44 & 1,98 & 2,02 & Barato \\
\hline Agradável & 4 & 2,3 & 2,14 & 2,36 & Desagradável \\
\hline Sensual & 2,36 & 2,22 & 1,94 & 2 & Recato \\
\hline Instigante & 2,34 & 2,54 & 2,34 & 2,42 & Monótono \\
\hline Moderno & 2,72 & 2,54 & 2,18 & 2,2 & Tradicional \\
\hline Alegre & 2,72 & 2,42 & 1,84 & 2,12 & Triste \\
\hline Indispensável & 3,14 & 2,92 & 3,12 & 3,48 & Substituível \\
\hline Simples & 3,46 & 3,8 & 4,28 & 1,74 & Vaidoso \\
\hline Discreto & 3,1 & 3,04 & 3,96 & 3,84 & Exagerado \\
\hline Bom & 2,16 & 2,34 & 2,1 & 2,34 & Ruim \\
\hline Calmo & 2,98 & 2,84 & 1,1 & 4,14 & Agitado \\
\hline Adequado & 2,4 & 2,34 & 2,32 & 2,56 & Inadequado \\
\hline
\end{tabular}

A questão seguinte destacou sete frases e usou a escala de Likert para responder e analisar o questionário de forma mais precisa, como indicado na tabela 6 os resultados em percentual. Em relação à frase "Eu compraria esse perfume pela marca", a média ficou em $39 \%$ no que se refere ao "Não concordo e nem discordo", o que mostra que não é de grande importância a marca, mas também não é um atributo que se descarta para comprar um perfume.

Em relação à frase "Eu compraria esse perfume porque já o consumo" $33 \%$ não concordaram e nem descordaram da frase em questão, ou seja, o hábito de consumir o mesmo perfume não é levado sempre em conta no que diz respeito a compra. A frase seguinte, "Eu compraria esse perfume pelo cheiro", ficou com uma média de $82 \%$ concordaram parcialmente e totalmente com a frase, ou seja, o fator odor, é de extrema importância na intenção de compra. Ao destacar a frase "Eu compraria esse perfume por indicação de uma celebridade", é possível perceber que os respondentes 30\% não concordam e nem discordam, mas $50 \%$ discordaram e discordaram totalmente, ou seja, há uma chance dos respondentes serem influenciados por celebridades, mas não é um fator decisório, e em sua maioria, preferem escolher pelo cheiro que o convém.

$\mathrm{Na}$ frase "Eu compraria esse perfume por uma lembrança que me fez recordar" teve $56 \%$ das respostas entre concordo e concordo totalmente, que indica que o maior fator de influência na intenção de compra está relacionado ao momento que o consumidor passou com aquele perfume ou marca. E por fim, a última frase, "Eu compraria esse perfume porque gostei da propaganda", teve $42 \%$ das respostas entre discordo e discordo totalmente, $29 \%$ não sabem se 
concordam ou não e $30 \%$ concordaram e concordaram totalmente com a questão, ou seja, a diferença entre os valores desses três blocos é pequena, mas o de maior destaque foi o que se concentra no bloco dos "discordo" e no "discordo totalmente". Relacionando com a questão 3, a propaganda é considerada "muito boa" e "boa", mas os respondentes não conseguiram concluir, se tomam uma decisão final de compra por conta de uma propaganda de perfume ou se não gostariam de se auto definir que são influenciados por uma propaganda de perfume.

Dividindo entre as duas marcas, em relação a pergunta "Eu compraria esse perfume pela marca", as propagandas do perfume Amor Amor da Cacharel, teve $7 \%$ que concordam totalmente e $23 \%$ apenas concordando com a frase. Já em relação ao perfume 212 VIP da marca Carolina Herrera, 12\% concordaram totalmente e $32 \%$ concordaram, ou seja, caso o respondente tenha feito a ligação dessa pergunta com a propaganda da marca Carolina Herrera ou da Cacharel assistido no questionário, pode se dizer que a marca mais bem avaliada em relação a intenção de compra é a da Carolina Herrera, que obteve valores maiores entre concordo e concordo totalmente.

Já em relação a pergunta "Eu compraria esse perfume porque gostei da propaganda", os valores encontrados nos questionários do perfume Amor Amor da Cacharel, indicaram que $7 \%$ concordam totalmente e $26 \%$ apenas concordam com a questão, quanto os questionários do perfume 212 VIP da marca Carolina Herrera, $5 \%$ concordam totalmente e $22 \%$ apenas concordam com a questão. Pode-se concluir um fato curioso, já que os valores encontrados nos questionários do perfume Amor Amor, pelo menos concordaram que comprariam um perfume porque gostou da propaganda, frente à $27 \%$ que pelo menos concordaram com a mesma questão, mas dos questionários do perfume 212 VIP. 
Tabela 6:

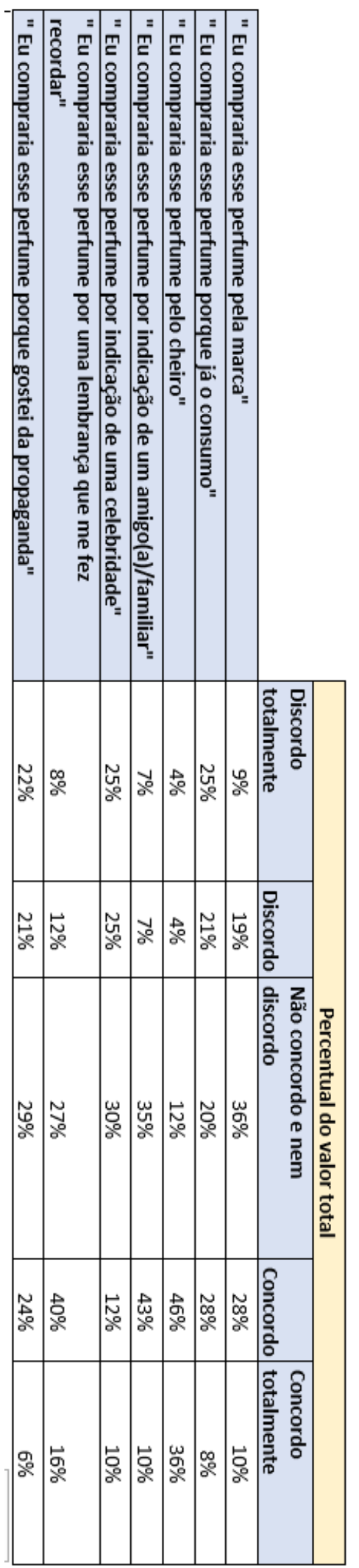




\section{Conclusões e recomendações para novos estudos}

No primeiro capítulo a pesquisa trata de assuntos sobre a importância das ferramentas como a música, nas propagandas e anúncios de perfumes para atrair o público desejado e captar novos de forma mais eficiente. Ainda no mesmo, o trabalho sinaliza os dados do mercado de perfume para agregar na pesquisa e análise desejada no estudo presente.

A pergunta de pesquisa foi de imensa importância, para entender o como a música de fundo numa propaganda de perfume pode influenciar na intenção de compra dos consumidores. Com o objetivo de analisar a relação entre a influência da música de fundo numa propaganda de perfume e a intenção de compra do consumidor. Vale destacar, que foi delimitada a análise de dois perfumes diferentes: 212 VIP da marca Carolina Herrera e Amor Amor da Cacharel, o diagnóstico f oi elaborado através da propaganda com música e sem música de cada perfume.

Para aprofundar a análise, foram estudadas as perspectivas do Schiffman e Kanuk (2010), destacando pontos sobre tomadas de decisão. Também foi utilizado Solomon (2011) abordando temas como comportamento do consumidor, tendência de utilização de plataformas na WEB nas propagandas, receptores sensoriais e alguns aspectos para entender sobre o comportamento do consumidor e também por Karsaklian (2011), que aborda temas sobre a intenção de compra do consumidor. Oakes (2007), Roehm (2011), Allan (2007) e Bullerjjhan (2006), foram utilizados para entender sobre a música de fundo nas propagandas e como estão relacionadas na vida e na intenção de compra dos consumidores.

Para atingir aos objetivos esperados realizou-se uma pesquisa quantitativa, por meio de quatro questionários estruturados, todos com a mesma estrutura e apenas com uma propaganda diferente. $O$ total coletado em cada questionário, foi de 50 respondentes para cada um, totalizando 200 amostras do banco de dados da plataforma MindMiners de forma aleatória.

Dentre as principais questões, destaca-se a diferença de notas entre um perfume para outro, pois as médias do perfume 212 VIP foram maiores do que a do Amor Amor, as propagandas sem músicas tiveram resultados menos 
favoráveis no que diz respeito às características do que as com a propaganda com música. Foi demonstrado que os respondentes ao perceberem uma propaganda sem música, dão notas mais baixas e conseguem destacar a música como o fator que esta falta na propaganda assistida.

Por fim, foi concluído que há uma grande importância em todo e qualquer detalhe na produção de uma propaganda de perfume para com as suas respectivas marcas. Podendo impactar na rejeição ou aceitação da marca e do produto, ou seja, fatores como a música e maiores informações do produto numa propaganda devem ter atenção redobrada no momento de sua produção, para atrair novos clientes, ser uma marca que fique na lembrança do sujeito e assim surgindo à oportunidade de novos clientes.

\subsection{Sugestões de futuras pesquisas}

Para futuros estudos, uma investigação mais profunda, isto é, um maior número de pesquisados na pesquisa e também uma maior variação no sentido de perfil dos sujeitos, abrangendo respondentes de outros estados brasileiros para que se possa obter resultados com maiores detalhes de seus comportamentos em relação ao mercado abordado, logo, com resultados mais amplos.

Outro ponto seria a análise de outras marcas de perfume, o presente estudo analisou duas marcas consideradas premium, logo, seria interessante analisar e se aprofundar também em propagandas de outras marcas de outras categorias, por exemplo brasileiras e outras de marcas populares. Essa variação de tipos de perfumes pode trazer outros olhares e atenção no momento de produzir uma propaganda de perfume.

Por fim, essa linha de estudo, pode ser desenvolvida a fundo para que as empresas de perfume consigam atingir seus públicos da melhor forma e com menor custo, sem que haja problema de rejeição à propaganda e, consequentemente, ao produto e marca. 


\section{Referências Bibliográfica}

ABIHPEC. Panorama do setor de higiene pessoal, perfumaria e cosméticos. 2016. Disponível em < https://www.abihpec.org.br/novo/category/publicacoes/panorama-do-setor/ > Acesso em: 25 Jun. 2017

ABIHPEC..Industria da beleza pode exportar mais. 2017. Disponível em: $<$ https://www.abihpec.org.br/novo/2014/06/industria-da-beleza-pode-exportarmais/ > Acesso em 12 Set. 2017

ALLAN, D. Effects of popular music in advertising on attention and memory. Journal of Advertising Research,, 2006.

ALLAN, D. Sound advertising: a review of the experimental evidence on the effects of music in commercials on attention, memory, attitudes, and purchase intention. Journal of Media Psychology, , 2007.

Anvisa - Legislação em vigilância sanitária, Rio de janeiro. Disponível em: $<$ http://portal.anvisa.gov.br > Acesso em 25 Jun. 2017

Aurélio, 2001 - Disponível em: < https://dicionariodoaurelio.com/ > Acesso em: 10 Set. 2017

BULLERJAHN, C. The effectiveness of music in television commercials - a comparison of theoretical approaches. In: BROWN, S. \& VOLGSTEN, U. (Eds.). Music and Manipulation: on the Social Uses and Social Control of Music. New York: Berghahn Books, 2006.

CNDL - Confederação nacional de dirigentes lojistas. Na crise, brasileiro escolhe cortar atividades de lazer em vez de gastos com beleza, SPC. Disponível em: < http://www.cndl.org.br/noticia/na-crise-brasileiro-escolhe-cortaratividades-de-lazer-em-vez-de-gastos-com-beleza-aponta-estudo-do-spc-brasil/> Acesso em 24 Jul. 2017

FONSECA, J. J. S. Metodologia da pesquisa científica. Fortaleza: UEC, 2002. Apostila.

HAWKINS, D. ; MOTHERSBAUGH, D. ; BEST, R. Comportamento do Consumidor: Construindo a Estratégia de Marketing.2007

MACKLIN, M. C. The relationship between music in advertising and children's responses: an experimental investigation. In: HECKER, S.; STEWART, D. W. (Eds.). Nonverbal communication in advertising. Lexington, MA: D. C. Heath, 1988. 
OAKES, S. Evaluating empirical research into music in advertising: a congruity perspective. Journal of Advertising Research, , 2007.

PETER, J.; OLSON, J. Comportamento do Consumidor e Estratégia de Marketing. 2009.

Revista Exame, Industria de cosmético dribla crise e projeta crescimento. Rio de Janeiro. Disponível em: <http://exame.abril.com.br/negocios/dino/industria-de-cosmeticos-dribla-crise-eprojeta-crescimento-dino890103433131/ > Acesso em 26 Jun. 2017

ROEHM, M. Instrumental vs. vocal versions of popular music in advertising. Journal of Advertising Research, May/June, , 2001.

Site de significados, Rio de Janeiro, 2017. Disponível em: <https://www.significados.com.br/jingle/ > Acesso em: 26 Jun. 2017

SOLOMON, Michael. O comportamento do consumidor: Comprando, Possuindo e sendo. 9 ed. Porto Alegre: Bookman, 2011.

SPC, Para driblar crise, brasileiro corta atividades de lazer e mantem gastos com beleza. Rio de Janeiro. Disponível em: < https://noticias.r7.com/economia/para-driblar-crise-brasileiro-corta-atividades-delazer-e-mantem-gastos-com-beleza-afirma-spc-02082016 > Acesso em: 16 Ago. 2017

Vídeo - Propaganda da Riachuelo com a Ludmilla. Citação do texto. Disponível em: < https://www.youtube.com/watch?v=hM81-Qg_OwA > 


\section{Anexo: Questionário}

As informações de sexo e idade já estavam atreladas ao banco de dados, por isso, as perguntas não entraram nos questionários.

1) Com que frequência você usa perfume?

- 7 vezes ou mais por semana

- $5-6$ vezes por semana

- 3 - 4 vezes por semana

- $1-2$ vezes por semana

- Não uso perfume

2) O que você pensa de pessoas que usam perfume? (Pode indicar mais de uma alternativa)

- São pessoas sofisticadas

- São pessoas vaidosas

- São pessoas que têm problemas com odor

- São pessoas esnobes

- São pessoas de personalidade forte

- São pessoas que tomam poucos banhos

- São pessoas sensuais

- São pessoas que buscam contato com o sexo oposto

- São pessoas que gostam de atrair a atenção

Nessa questão, aparecia o video da propaganda e logo abaixo a pergunta.

3) Dê uma nota (de 1 a 5) para a propaganda que você acabou de assistir:

- 1 - Muito Boa

- 2 - Boa

- 3 - Mediana

- 4-Ruim

- 5 - Muito Ruim

4) Em uma escala de 1 a 5, selecione o que mais se aproxima ao que você pensa do produto exibido na propaganda:

- Em cada opção, havia a escala de números de 1 à 5

- Sendo 1: Caro e 5: Barato

- Sendo 1: Agradável e 5: Desagradável

- Sendo 1: Sensual e 5: Recato

- Sendo 1: Instigante e 5: Monótono

- Sendo 1: Moderno e 5: Tradicional

- Sendo 1: Alegre e 5: Triste

- Sendo 1: Indispensável e 5: Substituível

- Sendo 1: Simples e 5: Vaidoso 
- Sendo 1: Discreto e 5: Exagerado

- Sendo 1:Bom e 5: Ruim

- Sendo 1: Calmo e 5: Agitado

- Sendo 1: Adequado e 5: Inadequado

5) O que faltou nessa propaganda para você ?

- Pergunta aberta

6) De acordo com as frases a seguir, responda:

- Em cada frase, havia as opções de responder:

- Discordo totalmente

- Discordo

- Não concordo e nem discord

- Concordo

- Concordo totalmente

- "Eu compraria esse perfume pela marca"

- "Eu compraria esse perfume porque já o consumo"

- "Eu compraria esse perfume pelo cheiro"

- "Eu compraria esse perfume por indicação de um amigo(a)/familiar"

- "Eu compraria esse perfume por indicação de uma celebridade"

- "Eu compraria esse perfume por uma lembrança que me fez recordar"

- "Eu compraria esse perfume porque gostei da propaganda"

7) Qual o bairro onde você reside atualmente?

- Pergunta aberta

8) Qual o seu grau de escolaridade?

- Sem escolaridade

- Fundamental incompleto

- Fundamental completo

- Ensino médio incompleto

- Ensino médio completo

- Ensino superior incompleto

- Ensino superior completo

- Pós-graduado incompleto

- Pós-graduado completo

9) Qual sua faixa de renda mensal familiar?

- Até $R \$ 1.576,00$

- De $R \$ 1.576,01$ a $R \$ 3.152,00$

- De $R \$ 3.152,01$ a $R \$ 7.880,00$

- De $R \$ 7.880,01$ a $R \$ 15.760,00$

- De $\mathrm{R} \$ 15760,01$ ou mais 